\title{
French Society of Digestive Endoscopy (SFED) Guidelines on performing a colonoscopy
}

B. Napoleon

T. Ponchon

R. R. Lefebvre

D. Heresbach

J. M. Canard

A. Calazel Benque

C. Boustiere

G. Gay

R. Laugier and members of the SFED board
Colonoscopy is the standard examination for diagnosing colorectal diseases and treating colorectal superficial neoplasms. Colonoscopy must be performed under the best conditions for optimum results. However, it is difficult to lay down rules as there is a scant amount of scientific data or available references on numerous points and because the practice is different from country to country, so that consulting the international literature is of limited use. Most of the options set out below are only the result of consulting experts. These guidelines are provisional and for guidance only as they are liable to change as and when new scientific information comes to light.

\section{Methodology}

The methodology recommended by the Haute Autorité de Santé (HAS) was used. A working party drew up an initial version of the guidelines. This was then submitted to a reading group. In order to make the consensus as broad as possible, the French Society of Digestive Endoscopy (SFED) widened the recommended reading group, and submitted the text to other scientific societies of the specialty. As there are few literature references and in the event of a difference of opinion among experts in the reading group, the SFED Board made the final choice.

\section{The following scientific societies were asked for their opinion:}

ANGH: Association Nationale des Hepatogastroenterologues Hospitaliers

CREGG: Club de Reflexion des Cabinets et Groupes d'Hepatogastroenterologie
FMC-HGE: Formation Medicale Continue -

Hepatogastroenterologie

SNFCP: Societe Nationale Francaise de Colo-proctologie

SNFGE: Societe Nationale Francaise de Gastroenterologie

SYNMAD: Syndicat des Maladies de l'Appareil Digestif

\section{Guidelines}

\section{Operator's qualifications}

A specific qualification in level I digestive endoscopy is required for performing a colonoscopy. This qualification can only be validated if the doctor acquired the certification in hepatogastroenterology.

When performing the examination, it is advisable to have an assistant present who is familiar with endoscopy. He or she can help when advancing the endoscope (abdominal pressure), performing diagnostic or therapeutic procedures, etc.

\section{Indication}

The indication for a colonoscopy must be made or confirmed by an hepatogastroenterologist, bearing in mind the patient's characteristics, the present state of knowledge and current guidelines.

Indications for endoscopy of the lower digestive tract, aside from population screening, were recently set out in the Clinical Practice Guidelines published under the authority of the HAS in 2004 [1]. 
When used for population screening, a colonoscopy is indicated in case of positive fecal occult blood test.

Colonoscopy is contraindicated if there is suspected perforation. The indication for a colonoscopy must be considered carefully in cases of confirmed pregnancy, suspected occlusion, severe inflammatory bowel disease, diverticulitis or known aortic aneurysm.

\section{Information to the patient}

In France, according to the law of 4 March 2002, "the patient must be given appropriate information about the risks and benefits of the examination so that he or she can give his informed consent". According to the recommendations of the Haute Autorité de Santé, this information must be given verbally, together with a written document such as the information sheet proposed by the SFED in conjunction with the SNFGE and the SNFCP. The information sheet does not need to be signed by the patient. Proof that the information has been given can be supplied by "any means". Written proof that the information has been given to the patient should be kept with the medical records. If an appended document must be signed by the patient, it can only validate the fact that the patient has received the information and that he was given an opportunity to ask any questions he liked. Alternatives are possible, such as a note in the medical records or in a letter to the attending doctor.

Apart from an emergency, reasonable application of the law of 4 March 2002 implies that information about the colonoscopy should be provided at a previous consultation, specific or not, carried out by an hepatogastroenterologist. The same applies to repeated colonoscopies.

At this consultation, essential questions regarding the risk of Creuzfeldt-Jakob's disease can be asked and the appropriate form on Creuzfeldt-Jakob's disease risk completed and be included with the records.

\section{Bowel preparation [1,3-7]}

This is a fundamental step for the examination. The consequences of poor preparation are manifold (unrecognized lesions, greater septic risk in case of perforation, need to repeat the examination, economic impact, etc.).

Apart from special cases, the bowel must be prepared orally using a product of proven effectiveness. The two most frequently used products at the moment are polyethylene glycol (PEG) and sodium phosphate.

Published studies show that there is no significant advantage in adding a non-fibrous diet. However, it may help to cut down on fiber residues which are likely to interfere with the examination. It is thus advisable and should be recommended for preparing patients for whom there is a risk of failure (hospitalized patients, those taking tricyclic antidepressants, with chronic constipation, etc.).

Due to the coloration they induce, it is advisable to withdraw drugs containing iron a week before the investigation.
In addition to a verbal explanation, the patient must have accurate written information about bowel preparation and any related diet.

There must be an interval between the final oral administration of the preparation product and anaesthesia so that the preparation is emptied from the stomach. The usual interval is three hours but this can vary according to the situation.

It is advisable to check the quality of the preparation before settling the patient. If stools or dirty fluid is still being emitted, there are various options to choose from: additional treatment by enema, postponed examination with extra oral preparation, etc.

During the examination, the presence of solid residue which cannot be suctioned is indicative of poor preparation; the operator must evaluate how damaging this is to the effectiveness and safety of the procedure and whether he can continue the examination or not, according to the circumstances. It is left to his judgement as to whether another examination is scheduled.

\section{Pre-colonoscopy blood test}

There are no guidelines on performing blood tests before a colonoscopy.

The SFED has asked the Study Group on Haemostasis and Thrombosis (GEHT) for guidelines to be put forward by specialists in haemostasis. Until this document is forthcoming, any blood tests are left to the judgement of the operator and the anaesthetist.

\section{Medical treatments \\ 6.1 Antithrombotic treatment}

Treatment should be adapted to comply with the guidelines on treatment with anticoagulants and antiplatelet agents [8], published in 2005 and drawn up in consultation with the SFED, the French Society of Anesthesiologist, the French Society of Cardiology and the GEHT.

\subsection{Other treatment}

At the anaesthesia consultation, treatments likely to interfere with the constraints of anaesthesia have to be adapted (anaesthetics used, fasting, etc.).

\section{Antibiotic prophylaxis}

Antibiotic prophylactic treatment should be carried out in accordance with the current guidelines (including the SFED guideline [9]) and with the anaesthetist.

\section{Anaesthesia}

The use of a general anaesthesia for colonoscopy has been demonstrated effective on acceptability for the patient but up to now not on the quality of the examination. In France, most examinations are performed under general anaesthesia with an anaesthetist present. All patients undergoing a colonoscopy must be offered a general anaesthesia. However, an examination without general anaesthesia is conceivable for patients who have been told about the potential pain. Intravenous sedation by a doctor who is not an anaesthetist is not recommended outside of clinical trials. 
When an anaesthesia is used, additional safety conditions inherent with this practice must be observed, in addition to those necessary for the colonoscopy itself. Specific information about anaesthesia is given to the patient during a specific consultation with an anaesthetist.

\section{Facilities}

If the patient received anaesthesia, the colonoscopy must be performed in an approved facility for anesthesia. If the patient does not receive anaesthesia, the hepatogastroenterologist is obliged to arrange the place, equipment and technical conditions for performing the procedure.

\section{Equipment}

\section{a) Endoscopes}

A colonoscope is most often used. A gastroscope, a rectosigmoidoscope, or an enteroscope (double balloon) may be preferable in particular situations.

There have been no scientific studies on correlations between obsolescence of the equipment and the quality of the examination. However, equipment should be upgraded regularly due to changing technology, particularly regarding the image.

Preventive maintenance of endoscopes is advisable. It should be adapted to take account of various factors (use, number of operators, age of the equipment, etc.)

The overall equipment must consist of several endoscopes so that there is sufficient time for cleaning and disinfecting the equipment in accordance with current legal requirements and to adapt to any unexpected technical fault rendering an endoscope unusable, without disrupting the endoscopy schedule and putting patients at a disadvantage.

\section{b) Accessories}

Biopsy forceps (AFSSAPS decision 18 June 2001) and injection needles for mucosectomy must be disposable. With regard to other accessories, circular DGS (Direction Generale de la Santé) 138 recommends that they should be disposable as soon as possible.

\section{c) Handling the equipment}

The procedures for cleaning, disinfecting and/or sterilising endoscopy equipment must be performed and recorded, in compliance with current legislation (circulars DGS 138 and 591). Cleaning/disinfecting procedures can be performed manually, semiautomatically or may be completely automatic (washers-disinfectors).

\section{d) Electrocoagulator}

There must be an electrocoagulator in every examination room.

The choice of equipment and how it is used are covered in an SFED guideline [10].

\section{The method for advancing the endoscope}

The examination is only regarded as complete if the caecum has been explored properly. Generally, it is advisable to advance the endoscope by visualising the lumen, by delooping, with limited inflation and suctioning any fluid which may be present. Almost without exception, the use of radioscopy is not recommended. Some maneuvers can sometimes be useful (changing the patient's position, abdominal pressure, etc.), particularly if there are circumstances which make advancement difficult (history of pelvic surgery etc. [11]).

\section{Examination of the mucosa $[1,12-24]$}

Examination of the mucosa must be very careful, circumferential and as complete as possible (particularly behind the haustrations). It is carried out when the endoscope is withdrawn, with alternating insufflation and exsufflation and by examining the mucosa on the way down and up. It must be looked for relief abnormalities (raised or depressed areas) but also for abnormalities in colour. Caecal and/or rectal retrovision may be used with caution.

The time spent on examining the colon as the colonoscope is withdrawn increases the method's sensitivity. A minimum of 6 minutes, apart from special cases, is recommended for exploring the mucosa when the endoscope is withdrawn.

Examination of the mucosa can be facilitated by chromoscopy. This is usually performed with indigo carmine applied to the mucosa. Two successive passages are necessary, first without chromoscopy then with chromoscopy, as a standard colonoscopy must first be performed to ensure that colour abnormalities which could be masked by the blue are not missed. It is recommended in screening for neoplastic lesions in very high-risk groups: HNPCC syndrome or attenuated familial adenomatous polyposis. While promising, application to long standing ulcerative colitis and Crohn's disease has still to be further evaluated before recommending chromoscopy to replace random biopsies. It can also be useful in identifying the extent of flat lesions or in investigating neoplastic residual foci after endoscopic resection.

It is advisable to exsufflate the colon at the end of the examination.

\section{Associated procedures}

1. Biopsies $[1,25]$

It is not advisable to systematically perform a biopsy of the ileum.

2. Resection of superficial neoplastic lesions [26]

Polypectomy and mucosectomy methods are described in specific SFED guidelines.

\section{Post-colonoscopic monitoring and detection of complications}

In addition to the monitoring specific to anaesthesia, monitoring of the endoscopic procedure itself must be performed by the operator or a member of the medical team before the patient is discharged so that any complications can be detected. A document must be given to the patient with post-examination instructions and the name and details of the person or institution to contact if he has any symptoms.

If there is any doubt about perforation, an abdomino-pelvic CT scan should be favoured over a plain X-ray of the abdomen, as 
soon as possible. Failing that, the indications for plain X-ray of the abdomen would still apply.

\section{Traceability}

All parameters of the endoscopic procedure must be registered. A guide to good practice on this subject is currently being compiled. At present, the following must be collected for each procedure: the patient's name, the type of procedure performed, the names of the medical and paramedical staff who performed the endoscopy and anaesthesia, the timetables, the references of the endoscope and batch numbers of the accessories used. The traceability of endoscope disinfection (manual or automatic) must also be recorded in detail (products, decontamination and disinfection times, etc.).

\section{Final report}

This is a key element in highlighting the quality of the procedure. It must give details of the indication, the technical conditions of the exploration (quality of the preparation, areas explored etc.), and the clinical outcome (location, size, number and accurate description of neoplastic lesions; description of non-neoplastic abnormalities: inflammatory lesions, diverticuli, angiodysplasia etc.). The description of neoplastic lesions can be standardized according to the Paris classification. It is advisable to have equipment for taking photographs.

\section{Final correspondence}

This has to be sent to the attending doctor. It should include the final report, histological results and any comments about the treatment or subsequent monitoring of the patient.

An additional letter can be sent to the patient automatically or in the absence of an attending doctor. It can contain a copy of the final report and appropriate explanatory comments, comments on histology and instructions on subsequent treatment or monitoring.

The results can also be delivered to the patient himself following the examination or at a later consultation. This dedicated consultation carried out by an hepatogastroenterologist, is recommended in cases of resection or biopsy of a malignant lesion (high-grade dysplasia, invasive cancer). The indications for this consultation can be extended, in particular, if a chronic inflammatory bowel disease is discovered.

\section{References}

${ }^{1}$ Recommandations pour la pratique clinique: Endoscopie digestive basse. Indications en dehors du dépistage en population. ANAES, avril 2004

${ }^{2}$ Information des patients. Recommandations destinées aux médecins. ANAES, mars 2000

${ }^{3}$ Ness RM, Manam R, Hoen H, Chalasani N. Predictors of inadequate bowel preparation for colonoscopy. Am J Gastroenterol 2001; 96: $1797-802$

${ }^{4}$ Harewood GC, Sharma VK, de Garmo P. Impact of colonoscopy preparation quality on detection of suspected colonic neoplasia. Gastrointest Endosc 2003; 58: 76 - 79
${ }^{5}$ Rex DK, Imperiale TF, Latinovich DR, Bratcher LL. Impact of bowel preparation on efficiency and cost of colonoscopy. Am J Gastroenterol 2002; 97: 1696 - 1700

${ }^{6}$ Kastenberg D, Chasen R, Choudhary C, Riff D, Steinberg S, Weiss E, Wruble L. Efficacy and safety of sodium phosphate tablets compared with PEG solution in colon cleansing: two identically designed, randomized, controlled, parallel group, multicenter phase III trials. Gastrointest Endosc 2001; 54: 705-713

${ }^{7}$ El Sayed AM, Kanafani ZA, Mourad FH, Soweid AM, Barada KA, Adorian CS et al. A randomized single-blind trial of whole versus split-dose polyethylene glycol-electrolyte solution for colonoscopy preparation. Gastrointest Endosc 2003; 58: 36-40

${ }^{8}$ Napoleon B, Boneu B, Maillard L, Samama CM, Schved JF, Gay G et al. Management of Patients on Anticoagulants or Antiplatelet Agents before Digestive Endoscopy. 2006; 38: 632 -638

${ }^{9}$ Barthet M, Napoleon B, Gay G, Ponchon T, Sautereau D, Arpurt JP et al. Antibiotic prophylaxis for digestive endoscopy. Endoscopy 2004; 36 : $1123-1125$

${ }^{10}$ Recommandation SFED: utilisation des électrocoagulateurs

${ }^{11}$ Anderson JC, Messina CR, Cohn W, Gottfried E, Ingber S, Bernstein G et al. Factors predictive of difficult colonoscopy. Gastrointest Endosc 2001; 54: $558-562$

12 Rex DK, Bond JH, Winawer S, Levin TR, Burt RW, Johnson DA et al. Quality in the technical performance of colonoscopy and the continuous quality improvement process for colonoscopy: recommendations of the U.S. Multi-Society Task Force on Colorectal Cancer. Am J Gastroenterol 2002; 97: 1296-1308

${ }^{13}$ Cutler CS, Rex DK, Hawes RH, Lehman GA. Does routine intravenous glucagon administration facilitate colonoscopy? A randomized trial. Gastrointest Endosc 1995; 42: 346-350

${ }^{14}$ Rex DK. Colonoscopic withdrawal technique is associated with adenoma miss rates. Gastrointest Endosc 2000; 51: 33 - 36

${ }^{15}$ Rex DK, Cummings OW, Helper DJ, Nowak TV, McGill JM, Chiao GZ et al. 5-year incidence of adenomas after negative colonoscopy in asymptomatic average-risk persons. Gastroenterology 1996; 111: $1178-1181$

${ }^{16}$ Shehadeh I, Rebala S, Kumar R, Markert RJ, Barde C, Gopalswamy N. Retrospective analysis of missed advanced adenomas on surveillance colonoscopy. Am J Gastroenterol 2002; 97: 1143 - 1147

${ }^{17}$ Hixson LJ, Fennerty MB, Sampliner RE, McGee D, Garewal H. Prospective study of the frequency and size distribution of polyps missed by colonoscopy. J Natl Cancer Inst 1990; 82: 1769-1772

${ }^{18}$ Rex DK, Cutler CS, Lemmel GT, Rahmani EY, Clark DW, Helper DJ et al. Colonoscopic miss rates of adenomas determined by back-to-back colonoscopies. Gastroenterology 1997; 112: 24-28

${ }^{19}$ Rembacken BJ, Fujii T, Cairns A, Dixon MF, Yoshida S, Chalmers DM, Axon AT. Flat and depressed colonic neoplasms: a prospective study of 1000 colonoscopies in the UK. Lancet 2000; 355: 1211 - 1214

${ }^{20}$ Suzuki N, Talbot IC, Saunders BP. The prevalence of small, flat colorectal cancers in a western population. Colorectal Dis 2004; 6: 15-20

${ }^{21}$ Kiesslich R, Fritsch J, Holtmann M, Koehler HH, Stolte M, Kanzler S et al. Methylene blue-aided chromoendoscopy for the detection of intraepithelial neoplasia and colon cancer in ulcerative colitis. Gastroenterology 2003; 124: 880-888

22 Rutter MD, Saunders BP, Schofield G, Forbes A, Price AB, Talbot IC. Pancolonic indigo carmine dye spraying for the detection of dysplasia in ulcerative colitis. Gut 2004; 53: 256-260

${ }^{23}$ Brooker JC, Saunders BP, Shah SG, Thapar CJ, Thomas HJ, Atkin WS et al. Total colonic dye-spray increases the detection of diminutive adenomas during routine colonoscopy: a randomized controlled trial. Gastrointest Endosc 2002; 56: $333-338$

${ }^{24}$ Hurlstone DP, Cross SS, Slater R, Sanders DS, Brown S. Detecting diminutive colorectal lesions at colonoscopy: a randomised controlled trial of pan-colonic versus targeted chromoscopy. Gut 2004; 53 : $376-380$

${ }^{25}$ Recommandations SFED: indication de la réalisation de biopsies lors d'une endoscopie digestive basse

${ }^{26}$ Recommandations SFED: polypectomie, mucosectomie 